\section{Lithium Neurotoxicity at Normal Serum Levels}

To the Editor: Lithium is used with great success in the treatment and prophylaxis of bipolar disorders, unipolar recurrent depression, and endogenous depression that is resistant to conventional treatment. It is also known to be neurotoxic at higher serum levels. In rare cases patients develop symptoms of intoxication even with normal lithium levels. ${ }^{1}$

\section{Case Report}

A 61-year-old man with history of bipolar disorder that was managed with lithium for more than 20 years presented with complaints of psychomotor slowdown, unsteady gait, memory deficits, restlessness, sleep disorder, and severe tremor in his hand that prevented him from eating or drinking properly. These symptoms had begun in the previous week. There was no recent history of fever, respiratory, gastrointestinal, or urinary complaints. He was medicated with lithium, $800 \mathrm{mg} /$ day, and fluvoxamine, $200 \mathrm{mg} /$ day, and the dosage of his medication had remained unchanged over the last year.

Neurological examination showed psychomotor slowdown, inattention, temporal disorientation, severe episodic memory impairment, motor and verbal perseveration, slurred speech, and hypophonia. Symmetrical global and segmental bradykinesia and lead-pipe rigidity, as well as tremor at rest, intention, and posture, were also evident. His gait was abnormal with shuffling small steps and a hunched-forward upper body.

An analytic study revealed no abnormalities, including $\mathrm{CBC}$, renal, thyroid and hepatic function, and PCR. Lithium serum levels were normal (1.0 mmol/liter).

EEG showed diffuse slow background activity, mainly at $5-6 \mathrm{~Hz}$, with periods of greater lentification at $3 \mathrm{~Hz}$, which is compatible with moderate to severe encephalopathy. A brain CT was normal. The patient was admitted and lithium was stopped. There was remarkable clinical improvement over the next days, and he was discharged at day 5, asymptomatic and on valproic acid (300 mg/day).

\section{Discussion}

Lithium-induced neuropsychiatric symptoms can be polymorphous and may be hard to differentiate from other disorders and other drug side effects. ${ }^{2}$ In chronic lithium intoxications, gastrointestinal symptoms are minimal or absent, and neurological abnormalities appear in the early phases. ${ }^{3}$ Increased toxicity in chronic lithium poisoning compared with other patterns of lithium exposure has been reported and is likely to be associated with higher tissue concentrations, which might not be readily discernable from serum lithium measurements alone. ${ }^{4} \mathrm{Sev}$ eral reports demonstrate a closer relationship between neurotoxic symptoms with EEG changes than with serum levels of lithium. ${ }^{5}$ In our patient the EEG was the only subsidiary examination indicating intoxication.

This case highlights the need for suspecting lithium-induced neurotoxicity based on the presence of clinical features of toxicity rather than laboratory investigations alone, as this can occur even at normal lithium serum levels.

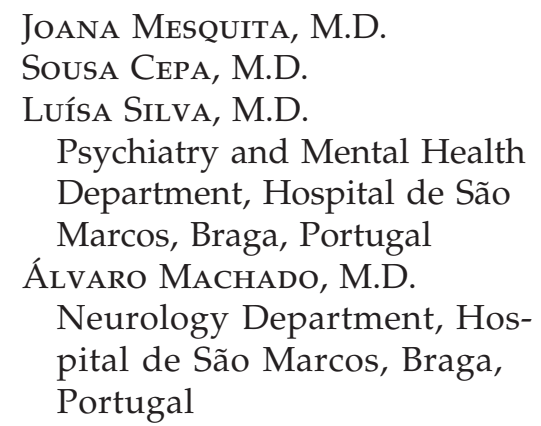

\section{References}

1. Habermeyer B, Hess M, KozomaraHocke $\mathrm{P}$, et al: Lithium intoxications at normal serum levels. Psychiatr Prax 2008; 35:198-200

2. Fallgatter AJ, Strik WK: Reversible neuropsychiatric side effects on lithium with normal serum levels: a case report. Nervenarzt $1997 ; 68: 568-590$

3. Pablo EH, Climent B, Escrivá DG, et al: Analysis of the poisonings by lithium in a department of internal medicine. An Med Interna 2008; 25:209-212

4. Waring WS, Laining WJ, Good AM, et al: Patterns of lithium exposure predicts poisoning severity: evaluation of referrals to a regional poisons unit. Q J Med 2007; 100:271-276

5. Gallinat J, Boetsch T, Padberg F, et al: Is the EEG helpful in diagnosing and monitoring lithium intoxication? A case report and review of the literature. Pharmacopsychiatry 2000; 33:169-173 